\title{
O ACESSO À JUSTIÇA E AS FORMAS ALTERNATIVAS DE RESOLUÇÃO DE CONFLITOS À LUZ DO NOVO CÓDIGO DE PROCESSO CIVIL
}

ACCESS TO JUSTICE AND ALTERNATIVE FORMS OF CONFLICT RESOLUTION IN THE LIGHT OF THE NEW CIVIL PROCESS CODE

Ana Carolina Zanini ${ }^{1}$

ISSUE DOI: 10.21207/1983.4225.404

\section{RESUMO}

O presente trabalho tem por objetivo analisar, através do método dedutivo, com técnica de pesquisa bibliográfica e documental, a evolução do acesso à justiça, bem como das formas alternativas de resolução de conflitos em relação à nova doutrina, além de entendimentos que possam ser flexibilizados ou alterados com base no Novo Código de Processo Civil. Analisando-se a evolução descrita, pretende-se delinear a problemática que surge não somente das lacunas, mas também do dinamismo da sociedade, que proporcionou uma mudança paradigmática da prioridade do meio litigioso para o consensual no Novo Código de Processo Civil. O Novo Código de Processo Civil traz, em seu texto, uma preferência pelas formas alternativas de resolução de conflitos, refletindo aquilo que a doutrina e a

\footnotetext{
${ }^{1}$ Advogada. Sócia fundadora do escritório Zanini Advogados Associados, atuante na região de Florianópolis/SC. Especialista em Direito de Família e das Sucessões. Especialista em Direito Processual Civil. Membro da Comissão de Direito de Família e Sucessões da OAB/SC. Membro da Comissão da Criança e do Adolescente da OAB/SC. Associada ao Instituto Brasileiro de Direito de Família. Telefone: (48) 99936-1030. E-mail: anazanini@zaniniadvogados.adv.br. Site: www.zaniniadvogados.adv.br.
} 
jurisprudência têm demonstrado como abordagem prioritária para a solução de controvérsias e de acesso à justiça. Ocorre paulatinamente uma mudança do paradigma litigioso para o consensual, com preferência às formas de diálogo entre as partes. Dessa forma, o acesso à justiça pode ser encarado como o requisito fundamental, o mais básico dos direitos humanos, de um sistema jurídico moderno e igualitário que pretenda garantir, e não apenas proclamar, os direitos de todos.

Palavras-chave: Acesso à justiça. Formas alternativas. Resolução de conflitos. Mediação. Conciliação. Flexibilizações. Entendimentos Jurisprudenciais. Adaptações. Tutela jurisdicional. Código de Processo Civil. Exoneração. Redução. Alteração.

\section{ABSTRACT}

This study aims to analyze, through the deductive method, with bibliographical and documentary research technique, the evolution of access to justice, as well as alternative forms of conflict resolution for the new doctrine, and understandings that can be smoothened or altered based on the New Code of Civil procedure. Analyzing the evolution described, it is intended to outline the problem that arises not only the gaps, but also the dynamism of society, which provided a paradigm shift of priority litigious means of the consensus in the New Code of Civil Procedure. The new Civil Procedure Code brings in its text a preference for alternative forms of conflict resolution, reflecting what the doctrine and jurisprudence have shown as priority for the settlement of disputes and access to justice. Gradually there is a change of the contested paradigm for consensus, with preference to forms of dialogue between the parties. Thus, access to justice can be seen as a fundamental requirement, the most basic of human rights, a modern and equitable legal system seeking to ensure, not only proclaim the rights of all.

Keywords: Access to justice. Alternative forms. Conflict resolution. Mediation. Conciliation. Flexibilities. Jurisprudential understandings. Adaptations. Judicial protection. Civil Procedure Code. Exemption. Reduction. Modification.

\section{INTRODUÇÃO}


O trabalho possui como tema central o acesso à justiça e a prevalência das formas alternativas de resolução de conflitos adotadas pelo Novo Código de Processo Civil. Para tal, faz-se breve explanação do histórico e conceito do acesso à justiça, o qual apresenta-se como a mais elementar garantia do processo e da própria jurisdição.

Além disso, o segundo capítulo aborda noções ao referido acesso, desdobrando-se em repercussões da crise na administração da justiça e no acesso formal e efetivo ao Judiciário.

O capítulo principal, e último, trata do acesso à justiça através das formas alternativas de resolução de conflitos previstas no Novo Código de Processo Civil, com enfoque na conciliação e mediação amplamente recepcionadas pelo diploma legal.

A conciliação e a mediação são formas pacificadoras de conflitos que buscam uma solução justa, através do diálogo das partes. Assim, o Novo Código de Processo Civil tem como um de seus objetivos trazer à tona tais meios pacificadores, diminuindo o tempo de vigência das ações e fazendo com que o acesso à justiça seja facilitado e simplificado.

Importante ressaltar que os artigos que tratam da mediação e da conciliação no Novo Código de Processo Civil estão distribuídos de forma dinâmica, demonstrando que os meios são potencialmente capazes de resolver os conflitos a qualquer tempo no processo.

$\mathrm{O}$ acesso à justiça deve ser encarado como o requisito fundamental, o mais básico dos direitos humanos, de um sistema jurídico moderno e igualitário que pretenda garantir, e não apenas proclamar, os direitos de todos.

O Novo Código de Processo Civil traz em seu texto uma preferência pelas formas alternativas de resolução de conflitos, refletindo aquilo que a doutrina e a jurisprudência vinham demonstrando como abordagem prioritária para a solução de controvérsias e de acesso à justiça.

\section{HISTÓRIA E CONCEITO DO ACESSO À JUSTIÇA}

Para ser entendida de modo mais claro a problematização do Acesso à Justiça, e de onde surgem as atuais dificuldades que a permeiam, há a necessidade de um breve contexto histórico sobre o surgimento, tanto do pensamento sobre o Acesso, quanto do conceito que este ocupava. 
O conceito de Acesso à Justiça surgiu na Grécia antiga, perante os debates filosóficos acerca do direito e com influências do jusnaturalismo, possuindo a isonomia como um de seus ideais. ${ }^{2}$

Os filósofos gregos formulavam questões a fim de exemplificar a justiça, como se pode observar na menção de Pedro Manuel Abreu:

A Escola de Pitágoras representava a justiça com a figura geométrica do quadrado, pela absoluta igualdade de todos os seus lados. Aristótoles formulou a teoria da justiça fundada na igualdade das razões influenciado pelo pensamento pitágorico (sobre peso, medidas de igualdade $\mathrm{e}$ proporcionalidade). Através da chamada régua de Lesbos, enunciou o conceito de equidade, evidenciando a possibilidade de o juiz adaptar a lei ao caso concreto. ${ }^{3}$

$\mathrm{O}$ aforismo grego influenciou o surgimento do sistema jurídico em Roma. E sucessivamente, o sistema romano-germânico, com destaque para a Lei de Constantino, que assegurava a gratuidade daqueles que necessitavam, prevista também ao Código de Justiano. ${ }^{4}$

Nos séculos XVIII e XIX, para defender o indivíduo contra governos despóticos, surgem os chamados "direitos humanos de primeira geração, que representavam, em essência, limites à intervenção do Estado na esfera individual. Tais direitos impõem ao Poder Público um dever de abstenção $[\ldots] " . .5$

Ainda sobre o tema, esclarecem Cappelletti e Garth:

À medida que as sociedades do laissez-faire cresceram em tamanho e complexidade, o conceito de direitos humanos começou a sofrer uma transformação radical. A partir do momento em que

\footnotetext{
${ }^{2}$ ABREU, Pedro Manuel. Acesso à justiça e juizados especiais. Florianópolis: Fundação Boiteux, 2004. p. 143.

${ }^{3}$ Ibidem. p. 46.

${ }^{4}$ Ibidem. p. 47.

${ }^{5}$ MARQUES, Alberto Carneiro. Perspectivas do processo coletivo no movimento de universalização do acesso à justiça. Curitiba: Juruá, 2007. p. 28-29.
} 
as ações e relacionamentos assumiram, cada vez mais, caráter mais coletivo que individual, as sociedades modernas necessariamente deixaram pra trás a visão individualista dos direitos, refletida nas "declarações de direitos", típicas dos séculos dezoito e dezenove. O movimento fez-se no sentido de reconhecer os direitos e deveres sociais dos governos, comunidades, associações e indivíduos. ${ }^{6}$

O direito sofreu fortes influências da religião, o poder advinha de um líder religioso, mais tarde dilatando-se ao legislador. Todos os fatos eram de certa forma, explicados por preceitos divinos. "Somente com o desenvolvimento das sociedades, nas quais se percebia um mínimo de estrutura organizacional, aclarou-se a separação entre os fenômenos religiosos daqueles político-sociais" é o que explica José Cichocki Neto. ${ }^{7}$

$\mathrm{O}$ acesso à justiça obteve maior destaque no século XX. Pedro Manuel Abreu explica que isso decorre em razão:

[...] dos novos direitos sociais e o surgimento das constituições dirigentes, havendo reiteradas denúncias do funcionamento insatisfatório da justiça na Alemanha e na Áustria, pela incapacidade de atendimento da demanda judicial, sendo várias as tentativas de minimizar o problema, protagonizadas tanto pelo Estado como por setores organizados das classes sociais mais débeis. ${ }^{8}$

Neste norte, Sérgio Ricardo de Souza afirma em artigo à Revista do Tribunal de Justiça do Estado do Maranhão:

Com o advento da Constituição de 1988, a sociedade brasileira viu surgirem novos direitos, concebidos internacionalmente principalmente a partir da $2^{\mathrm{a}}$

${ }^{6}$ CAPPELlETTI, Mauro; GARTH, Bryan. Acesso à Justiça. Tradução e revisão de Ellen Gacie Northfleet. Porto Alegre: Sergio Antonio Fabris Editor, 1988. p. 10-11.

${ }^{7}$ CICHOCKI NETO, José. Limitações do Acesso à Justiça. 1 ed., 3 tir. Curitiba: Juruá, 2002. p. 51.

${ }^{8}$ ABREU, Pedro Manuel. Acesso à justiça e juizados especiais. Florianópolis: Fundação Boiteux, 2004. p. 47-48. 
Guerra Mundial e que ultrapassam os limites conceituais das tradicionais demandas de cunho individual, tradicionalmente solucionados em conformidade com as diretrizes da lógica formal típica do modelo cartesiano e do positivismo, com predominância da idéia de que ao Poder Judiciário cabe aplicar a lei ao caso concreto, solucionando formalmente a lide, sem lhe caber questionar ou pretender analisar aspectos sociológicos vinculados à efetividade da intervenção jurisdicional, no que concerne à pacificação social. ${ }^{9}$

Com as mudanças sofridas, referente aos novos direitos sociais e ao surgimento das constituições fez-se necessário a modificação das regras. Dessa forma, o Poder Estatal passou a ter a capacidade que lhe era necessária para solucionar os novos conflitos e atender o aumento da demanda dos litígios.

O ser humano tem naturalmente uma vontade de resolver seus problemas para fazer, afinal, valer seus direitos. Nisso, encontra-se o conceito de acesso à justiça e o indivíduo deverá recorrer ao Poder Estatal para a resolução de sua lide.

Neste norte, Alberto Carneiro Marques ensina que:

$\mathrm{O}$ acesso à justiça, apresenta-se como a mais elementar garantia do processo e da própria jurisdição, porquanto materializa a garantia constitucional de que o cidadão obterá dos poderes constituídos o respeito aos seus direitos e à pronta restauração daqueles que lhe forem violados. ${ }^{10}$

Contudo, para que ocorra um efetivo ingresso ao ordenamento jurídico brasileiro, o Estado deve proporcionar condições necessárias que contemplem todos os indivíduos. Dessa forma, o acesso à justiça pode ser

\footnotetext{
${ }^{9}$ SOUZA, Sérgio Ricardo de. Mediação e conciliação: eficazes instrumentos de complementação ao sistema judicial clássico: Revista do Tribunal de Justiça do Estado do Maranhão v. 3, n. 3, jan/jun. 2009. p. 62

${ }^{10}$ MARQUES, Alberto Carneiro. Perspectivas do processo coletivo no movimento de universalização do acesso à justiça. Curitiba: Juruá, 2007. p. 26-27.
} 
encarado como o requisito fundamental, o mais basilar dos direitos humanos.

\section{NOÇÕES DO ACESSO À JUSTIÇA}

"A todos é garantido o pleno acesso à justiça.". ${ }^{11}$ É esta a base de todo o ensino teórico jurisdicional, e, além, embasamento para os princípios que regem o referido acesso, em sua forma ampla ou estrita, ou seja, tanto em informatização, quanto em ter meios para demandar ao judiciário.

Como já é coerentemente explicado por Cappelletti e Garth, é difícil a formulação de um conceito ou de uma definição, porém o mínimo necessário é que se determinem quais são as finalidades básicas do sistema jurídico, sendo "o sistema pelo qual as pessoas podem reivindicar seus direitos e/ou resolver seus litígios sob os auspícios do Estado". ${ }^{12}$

Desta forma, torna-se evidente que o sistema deve propor condições básicas para que todos, igualmente, possuam formas para acessar o judiciário, para assim ter a resolução da lide pretendida sem discrepâncias, sejam elas culturais, sociais, ou econômicas.

É mister assinalar que o Acesso à Justiça sofre mudanças em concordância com as que são sofridas, também, pelo processo civil, porém sempre se atinando ao que é expresso pela Lex Mater.

A Constituição Federal de 1988 prevê em seu art. 5, XXXV que "a lei não excluirá da apreciação do Poder Judiciário lesão ou ameaça a direito". Em outras palavras, todos que desejam, podem pleitear suas lides aos órgãos judiciais, respeitando as normas vigentes.

O Acesso à Justiça é um direito fundamental, que, em teoria, garante a todos uma solução para seus litígios de forma satisfatória. É um instrumento Estatal, que possui o intuito de proporcionar o direito de ação processual, concominante a uma decisão que satisfaça as partes.

Sob esse prisma, é vedado ao legislador impedir qualquer pessoa que tenha o seu direito lesado, ou está ameaçado a tê-lo, a proteção do Poder Judiciário. Isto é também explicitado pelo autor Rui Portanova,

\footnotetext{
${ }^{11}$ PORTANOVA, Rui. Princípios do Processo Civil. $7^{\text {a }}$ ed. Porto Alegre: Porto Alegre. 2008. p. 112.

${ }^{12}$ CAPPELLETTI, Mauro; GARTH, Bryan. Acesso à Justiça. Tradução e revisão de Ellen Gacie Northfleet. Porto Alegre: Sergio Antonio Fabris Editor, 1988. p. 8.
} 
como pode-se ver em tal seguimento, quando trata do Poder Judicário: "Sendo um Poder com anseios democráticos, está aberto a todos, inclusive para aqueles que não podem pagar seus custos operacionais". ${ }^{13}$

$\mathrm{O}$ acesso à justiça além de ser um direito fundamental, por ter garantias elencadas na Carta Magna, é também considerado como um requisito essencial para o bom funcionamento de todo Ordenamento Jurídico, bem como instrumento de efetivação da cidadania.

É importante ressaltar que conforme ocorrem mudanças na sociedade, devem ocorrer mudanças no Ordenamento, a fim de proporcionar uma maior adaptação. Como é aprofundado pelo autor Eugen Ehrlich, 1929, em seu livro "Estudo do Direito Vivo", traduzido por Francisco Luiz Pitta Marinho, não se deve observar somente a lei, é de suma importância a análise da realidade concreta, pois apenas pela Práxis, ou seja, pela prática humana consciente, é que ocorrerá a concretude dos fenômenos jurídicos. É o que afirma no seguinte trecho: "Para conhecer o estado real do direito, temos que investigar o que a sociedade humana produz, como também o direito estatal e a influência real do Estado sobre o direito social". ${ }^{14}$

Ehrlich afirma, neste mesmo texto, que o que é visto hoje é uma síntese de todo o passado, ou seja, é perceptível o caráter dinâmico da lei quando são analisadas as mudanças sofridas por ela até o momento. E também em se tratando da sociedade, é perceptível uma mutabilidade em decorrência do pensamento que se transcendeu, e consequentemente, há essa dinamicidade jurisdicional já referida. É o que se pode perceber nesta passagem do seu texto "O Estudo do Direito vivo":

[...] o caminho para o entendimento da mais íntima essência do presente está numa olhadela no passado; em cada parte do presente está contido todo seu passado, o qual pode ser claramente reconhecível para o olho que ver nesta profundidade. ${ }^{15}$

\footnotetext{
${ }^{13}$ PORTANOVA, Rui. Princípios do Processo Civil. $7^{\text {a }}$ ed. Porto Alegre: Porto Alegre. 2008. p. 62.

${ }^{14}$ EHRLICH, Eugen. Fundamentos da Sociologia do Direito. Trad. de René Ernani Gertz. Brasília: Universidade de Brasília, 1986. p. 114.

${ }^{15}$ Ibidem. p. 115.
} 
Desta forma, Ehrlich parte de um pressuposto que o direito constitui a essência da vida social, assim, é de suma importância que sejam levados em consideração os fatos alheios às normas positivadas, pois somente desta maneira, analisando-se os fenômenos socioeconômicos, os problemas serão solucionados de forma eficaz e equânime. E somente assim haverá também uma abordagem crítica e dinâmica em relação aos fenômenos jurídicos.

É, de fato, muito vasta a lista de renomes do direito que trataram sobre o Acesso à Justiça, até mesmo pelo fato de que é um assunto concernente também à sociologia, à antropologia, às ciências políticas e sociais, além de muitos outros. Pois a Justiça, seu acesso, suas formas, e suas problemáticas, se encontram atrelados à sociedade. É visível a dinamicidade entre ambos, e, da sociedade, surgem todos os questionamentos, dificuldades e embasamento para o estudo de tais disciplinas, entre outras.

\subsection{ACESSO À JUSTIÇA NO BRASIL - CRISE DA ADMINISTRAÇÃO DA JUSTIÇA}

O movimento do acesso à justiça encontra forças no Brasil desde a década de 1980, conhecido como o movimento de democratização de acesso a justiça. É um movimento que faz suas considerações sobre a processualística nacional, constatando se a mesma atua de forma a facilitar ou dificultar o acesso numa sociedade com tamanha disparidade social.

O Brasil da crise da administração da justiça era um Brasil que apresentava conflitos variados de um crescimento desordenado, oriundos de um processo de industrialização forçado, também provenientes de crises econômicas que dentre outros motivos, tiveram como fator deflagrante o petróleo. Estas desordens geraram diversos conflitos que culminaram em uma enorme litigiosidade entre vários grupos sociais. A exclusão dos desprovidos de renda para pagar as despesas processuais já é evidente neste período, e a solução encontrada por estes para resolução de litígios é procurar formas alternativas, sem intervenção do judiciário, visto que a este não tinham acesso. Então, a alternativa era procurar ajuda com o pastor, líder sindical, ou alguma outra liderança comunitária chegando até mesmo a buscar serviços de um justiceiro: 
O código de Processo Civil é uma obra monumental em homenagem ao princípio do contraditório e da ampla defesa, mas não firmou compromisso com o acesso à justiça pelas populações carentes que têm pretensões de pequeno valor econômico nem com a prestação jurisdicional para as massas a imensa burocracia processual do CPC que significa, na Justiça Federal, juntada de milhares de petições, expedição de milhares de mandados e requer um exército de servidores pagos pelos cofres públicos se houver a real pretensão de se cumprir os prazos legais. ${ }^{16}$

A disposição do código de processo civil dificultava o acesso do pobre ao judiciário com seus altos custos e burocracia, envolvendo a profissão dos advogados e demais membros do judiciário, pois, à época, não se trabalhava de forma crítica, com análise personalizada de cada caso concreto, mas sim com rotinas técnicas executadas friamente. ${ }^{17}$

\subsection{ACESSO FORMAL E EFETIVO}

$\mathrm{O}$ acesso à justiça é um direito fundamental. Assinala Boaventura de Souza Santos que "o tema do acesso à justiça é aquele que mais diretamente equaciona as relações entre o processo civil e a justiça social, entre igualdade jurídico-formal e desigualdade sócio-econômica". ${ }^{18}$

Além disso, é o foco da moderna processualística, tendo por objetivo aprofundar o estudo das metas e métodos do direito moderno. ${ }^{19}$

\footnotetext{
16 ALMEIDA, Selene Maria de. O paradigma processual do liberalismo e o acesso à justiça. Revista CEJ, Brasília, n. 22, p. 20-24, jul./set. 2003. p. 21.

${ }^{17}$ Ibidem. p. 23.

${ }^{18}$ CAPPELLETTI, Mauro; GARTH, Bryan. Acesso à Justiça. Tradução e revisão de Ellen Gacie Northfleet. Porto Alegre: Sergio Antonio Fabris Editor, 1988. p. 115.

${ }^{19}$ SANTOS, Boaventura de Souza. Para uma revolução democrática da justiça. $2^{\mathrm{a}}$ ed. São Paulo: Cortez, 2008. p. 167.
} 
Finalmente, Rui Portanova acentua que o Princípio do acesso à justiça "é um movimento para efetividade e igualdade material almejada por todos e consagrada pelo Estado Social". ${ }^{20}$

$\mathrm{O}$ acesso à justiça é garantido na Constituição Federal na forma do inciso XXXV, artigo $5^{\circ 21}$. O Supremo Tribunal Federal definiu a questão do acesso à justiça: "A garantia constitucional alusiva ao acesso ao Judiciário engloba a entrega da prestação jurisdicional de forma completa, emitindo o Estado-juiz entendimento explícito sobre as matérias de defesa veiculadas pelas partes". ${ }^{22}$

A questão de acessibilidade vem para adequar o direito ao atual momento vivido na sociedade, à democracia, abrindo os caminhos do judiciário para a população, possibilitando sua busca por direitos.

\section{3 \\ O ACESSO À JUSTIÇA ATRAVÉS DAS FORMAS ALTERNATIVAS DE RESOLUÇÃO DE CONFLITOS NO NOVO CÓDIGO DE PROCESSO CIVIL}

A conciliação e a mediação são formas pacificadoras de conflitos que buscam uma solução justa, através do diálogo das partes. Assim, o Novo Código de Processo Civil, em vigor desde março de 2016, tem como

${ }^{20}$ PORTANOVA, Rui. Princípios do Processo Civil. $7^{\text {a }}$ ed. Porto Alegre: Porto Alegre. 2008. p. 112.

${ }^{21}$ XXXV- a lei não excluirá da apreciação do Poder Judiciário, lesão ou ameaça a direito.”. São complementares ao dispositivo central no que se sustenta o direito do acesso à justiça, outros incisos do mesmo artigo $5^{\circ}$, a saber:

LV - aos litigantes, em processo judicial ou administrativo, e aos acusados em geral são assegurados o contraditório e ampla defesa, com os meios e recursos a ela inerentes;

LXXIII - qualquer cidadão é parte legítima para propor ação popular que vise a anular ato lesivo ao patrimônio público ou de entidade de que o Estado participe, à moralidade administrativa, ao meio ambiente e ao patrimônio histórico e cultural, ficando o autor, salvo comprovada má-fé, isento de custas judiciais e do ônus da sucumbência;

LXXIV - o Estado prestará assistência jurídica integral e gratuita aos que comprovarem insuficiência de recursos;

LXXVII - são gratuitas as ações de "habeas-corpus" e "habeas-data", e, na forma da lei, os atos necessários ao exercício da cidadania.

LXXVIII - a todos, no âmbito judicial e administrativo, são assegurados a razoável duração do processo e os meios que garantam a celeridade de sua tramitação.

22 BRASIL. Superior Tribunal de Justiça. Recurso Especial n. 172.084. Disponível em <www.stj.jus.br> Acesso: 27/05/2016. 
objetivo trazer à tona tais meios pacificadores, diminuindo o tempo de vigência das ações e fazendo com que o acesso à justiça seja facilitado e simplificado.

A experiência conciliadora constante nos Juizados Especiais desde a entrada em vigor da Lei n. 9.099/1995 é levada de forma destacada ao Novo Código de Processo Civil, para ser aplicada em todas as lides da Justiça Comum.

$\mathrm{O}$ art. $3^{\circ}, \S 2^{\circ}$, do Novo Código de Processo Civil estabelece que "O Estado promoverá, sempre que possível, a solução consensual dos conflitos", constante, assim, como uma norma fundamental do processo civil.

No mesmo artigo supracitado, em seu $\S 3^{\circ}$, a lei dá ênfase às formas alternativas de resolução de conflitos, ex vi: "A conciliação, a mediação e outros Métodos de Solução Consensual de Conflitos deverão ser estimulados por juízes, advogados, defensores públicos e membros do Ministério Público, inclusive no curso do processo judicial”.

Os artigos que tratam da mediação e da conciliação no Novo Código de Processo Civil estão distribuídos de forma dinâmica, demonstrando que os meios são potencialmente capazes de resolver os conflitos a qualquer tempo no processo.

O doutrinador Roberto Portugal Bacellar (1999, p. 125) explica que "estes institutos trazem o desafogamento do Judiciário, permitindo que os julgadores se voltem para questões mais complexas, podendo analisar caso a caso de forma fundamentada".

O Código de Processo Civil de 1973 contava apenas da conciliação como meio processual, sendo a mediação uma pioneira, bem como a inclusão de mediadores e conciliadores judiciais como auxiliares da justiça. $^{23}$

Delineado pelos seus idealizadores desde o Projeto de Lei $\mathrm{n}^{\circ}$ 8046/10, bem como pela sua respectiva Exposição de Motivos "deu-se ênfase à possibilidade de as partes porem fim ao conflito pela via da mediação ou da conciliação.

\footnotetext{
${ }^{23}$ TARTUCEb, Fernanda. Processos Judiciais e Administrativos em Direito de Família. In PEREIRA, Rodrigo da Cunha (organizador). Tratado de Direito das Famílias. Belo Horizonte: IBDFAM, 2015. cap. 21. p. 903.
} 
Entendeu-se que a satisfação efetiva das partes pode dar-se de modo mais intenso se a solução é por elas criada e não imposta pelo juiz" (Exposição de Motivos da Lei n. 13.105/2015). ${ }^{24}$

Além do mais, a "interdisciplinaridade dos meios consensuais está reconhecida no dispositivo que dispõe que o juiz deve dispor 'do auxílio de profissionais de outras áreas de conhecimento para a mediação e conciliação". ${ }^{25}$

O Novo Código, portanto, "aponta para a mediação ou conciliação judicial, que acontece de forma organizada e promovida pelo Poder Judiciário (court-annexed mediation, na língua inglesa), sendo a forma pela qual mais comumente os meios consensuais têm-se desenvolvido no país". 26

Continua a doutrinadora, ainda:

Ao ponto, vale lembrar que a mediação geralmente é desenvolvida em mais de uma sessão, porque precisam ser abordados diversos pontos controvertidos do histórico dos envolvidos; já a conciliação costuma contar apenas com um ou dois encontros porque a relação é episódica, sendo a disputa trabalhada sob uma vertente mais pontual. ${ }^{27}$

Deve-se destacar que a escolha do meio utilizado para solucionar os conflitos é das partes envolvidas, assim, há maior importância da conscientização dos cidadãos para optarem pela maneira que melhor lhes aprouver.

Nesse sentido, Kasuo Watanabe destaca que "a redução dos processos judiciais é muito importante, mas ela é uma consequência da pacificação das partes conflitantes". ${ }^{28}$

24 BRASIL. Lei n. 13.105. Código de Processo Civil. Disponível em <www.planalto.gov.br>. Acesso: 27/05/2016.

${ }^{25}$ TARTUCEb, Fernanda. Processos Judiciais e Administrativos em Direito de Família. In PEREIRA, Rodrigo da Cunha (organizador). Tratado de Direito das Famílias. Belo Horizonte: IBDFAM, 2015. cap. 21. p. 903.

${ }^{26}$ Ibidem.

${ }^{27}$ Ibidem.

${ }^{28}$ WATANABE, Kasuo. Poder de conciliação desafoga o Judiciário e pacifica as relações sociais. 2011. Disponível em <www.direitolegal.org>. Acesso: 26/05/2016. p. 38. 
Para que a resolução do conflito dependa dos envolvidos, a doutrinadora Fernanda Tartuce argumenta que é preciso haver maior maturidade destes novos protagonistas:

Espera-se que as pessoas estejam prontas para ser protagonistas de seus destinos e consigam reconhecer a valiosa oportunidade de construção conjunta viabilizada pela mediação. Para tanto, será importante que se permitam participar de ulteriores sessões, sendo primordial que seus advogados contribuam em seu convencimento destacando as vantagens da solução consensual especialmente em relação a fatores como tempo, satisfação e cumprimento espontâneo dos pactos. ${ }^{29}$

Por outro lado, cabe ressaltar que a audiência de conciliação ou mediação é uma faculdade das partes, mais precisamente do autor da ação, conforme disposto no art. 319 , VII. ${ }^{30}$

A controvérsia passa a ser vista, portanto, como uma oportunidade de transformação, sendo que "a pacificação social, importante e complexa missão constitucional do Estado, será mais bem alcançada com a participação ativa, em sua composição, de todos os envolvidos no conflito". ${ }^{31}$

Conclui-se ser evidente que, de acordo com a necessidade e o dinamismo da sociedade, passou-se a propor condições básicas para que todos, igualmente, possuam formas para acessar o judiciário, para assim ter a resolução da lide pretendida sem discrepâncias, sejam elas culturais, sociais, ou econômicas.

Crescendo aceleradamente, os institutos das formas alternativas de resolução de conflitos elevam o desempenho das atividades, contornando a morosidade do processo e fornecendo maior bem estar aos cidadãos.

\footnotetext{
${ }^{29}$ TARTUCEb, Fernanda. Processos Judiciais e Administrativos em Direito de Família. In PEREIRA, Rodrigo da Cunha (organizador). Tratado de Direito das Famílias. Belo Horizonte: IBDFAM, 2015. cap. 21. p. 903.

${ }^{30}$ Art. 319. A petição inicial indicará:

VII - a opção do autor pela realização ou não de audiência de conciliação ou de mediação.

31 TARTUCEa, Fernanda. Mediação nos conflitos civis. Rio de Janeiro: Forense; São Paulo: MÉTODO, 2015. p. 307.
} 
Pautado em tais direitos, o Novo Código de Processo Civil traz em seu texto uma preferência pelas formas alternativas de resolução de conflitos, refletindo aquilo que a doutrina e a jurisprudência têm demonstrado como abordagem prioritária para a solução de controvérsias e de acesso à justiça.

\section{CONSIDERAÇÕES FINAIS}

A legislação, seja tratando de conteúdo material ou processual, deve evoluir com o dinamismo da sociedade. As mudanças, sendo absorvidas mais rapidamente pelo poder judiciário, são analisadas primeiramente no caso concreto pelos magistrados na busca da efetiva tutela jurisdicional.

O assunto "acesso à justiça", com o passar dos anos ficou cada vez mais ligado às formas alternativas de resolução de conflitos, propondo condições básicas para que todos, igualmente, possuam formas para acessar o judiciário, para assim ter a resolução da lide pretendida sem quaisquer discrepâncias.

O Acesso à Justiça é um direito fundamental, que visa garantir a todos uma solução para seus litígios de forma satisfatória. É um instrumento estatal, que possui o intuito de proporcionar o direito de ação processual, concominante a uma decisão que satisfaça as partes.

É mister assinalar que o Acesso à Justiça sofre mudanças em concordância com as que são sofridas, também, pelo processo civil, porém sempre se atinando ao que é expresso pela Lex Mater.

Dessa forma, o acesso à justiça pode ser encarado como basilar dos direitos humanos, garantindo efetivamente os direitos de todos.

O Novo Código de Processo Civil traz em seu texto uma preferência pelas formas alternativas de resolução de conflitos, refletindo aquilo que a doutrina e a jurisprudência vinham demonstrando como abordagem prioritária para a solução de controvérsias e de acesso à justiça.

As formas alternativas de resolução de conflitos revelaram-se como tendência, pois de forma célere e econômica, elevam o desempenho das atividades e contornam a morosidade processual, superando barreiras que excluem as pessoas do acesso à justiça. 
Ocorre, paulatinamente, uma mudança do paradigma litigioso para o consensual, com preferência às formas de diálogo entre as partes, tornando o sistema judiciário mais ágil e acessível.

\section{REFERÊNCIAS BIBLIOGRÁFICAS}

BRASIL. Constituição da República Federativa do Brasil. Disponível em <www.planalto.gov.br> Acesso: 27/05/2016.

- Superior Tribunal de Justiça. Lei n. 13.105. Código de Processo Civil. Disponível em <www.planalto.gov.br > . Acesso: 27/05/2016.

. Recurso Especial n. 172.084. Disponível em <www.stj.jus.br> Acesso: 27/05/2016.

ABREU, Pedro Manuel. Acesso à justiça e juizados especiais. Florianópolis: Fundação Boiteux, 2004.

BACELLAR, Roberto Portugal. A mediação no contexto dos modelos consensuais de resolução de conflitos. REPRO: Revista de Processo, São Paulo: Revista dos Tribunais, n. 95, jul./set. 1999.

CAPPELLETTI, Mauro; GARTH, Bryan. Acesso à Justiça. Tradução e revisão de Ellen Gacie Northfleet. Porto Alegre: Sergio Antonio Fabris Editor, 1988.

EHRLICH, Eugen. Fundamentos da Sociologia do Direito. Trad. de René Ernani Gertz. Brasília: Universidade de Brasília, 1986.

MARQUES, Alberto Carneiro. Perspectivas do processo coletivo no movimento de universalização do acesso à justiça. Curitiba: Juruá, 2007.

NETO, José Cichocki. Limitações do Acesso à Justiça. 1 ed., 3 tir. Curitiba: Juruá, 2002.

PORTANOVA, Rui. Princípios do Processo Civil. $7^{\text {a }}$ ed. Porto Alegre: Porto Alegre. 2008.

SANTOS, Boaventura de Souza. Para uma revolução democrática da justiça. $2^{a}$ ed. São Paulo: Cortez, 2008.

SOUZA, Sérgio Ricardo de. Mediação e conciliação: eficazes instrumentos de complementação ao sistema judicial clássico: Revista do Tribunal de Justiça do Estado do Maranhão v. 3, n. 3, jan/jun. 2009, p. 62

TARTUCEa, Fernanda. Mediação nos conflitos civis. Rio de Janeiro: Forense; São Paulo: MÉTODO, 2015. 
TARTUCEb, Fernanda. Processos Judiciais e Administrativos em Direito de Família. In PEREIRA, Rodrigo da Cunha (organizador). Tratado de Direito das Famílias. Belo Horizonte: IBDFAM, 2015. cap. 21, pp. 901-994.

WATANABE, Kasuo. Poder de conciliação desafoga o Judiciário e pacifica as relações sociais. 2011. Disponível em <www.direitolegal.org>. Acesso: 26/05/2016. 
